\title{
Sludge volume index and suspended solids estimation of mature aerobic granular sludge by quantitative image analysis and chemometric tools
}

\author{
Cristiano Leal ${ }^{\mathrm{a}}$, Angeles Val del Río ${ }^{\mathrm{a}}$, Daniela P. Mesquita ${ }^{\mathrm{a}, *}$, António L. Amaral ${ }^{\mathrm{a}, \mathrm{b}}$, \\ Paula M.L. Castro ${ }^{c}$, Eugénio C. Ferreira ${ }^{a}$ \\ ${ }^{\text {a }}$ CEB - Centre of Biological Engineering, Universidade do Minho, Campus de Gualtar, 4710-057 Braga, Portugal \\ ${ }^{\mathrm{b}}$ Instituto Politécnico de Coimbra, ISEC, Rua Pedro Nunes, Quinta da Nora, 3030-199 Coimbra, Portugal \\ ${ }^{\mathrm{c}}$ Universidade Católica Portuguesa, CBQF - Centro de Biotecnologia e Química Fina - Laboratório Associado, Escola Superior de Biotecnologia, Rua Diogo Botelho 1327, \\ 4169-005 Porto, Portugal
}

\section{A R T I C L E I N F O}

\section{Keywords:}

Aerobic granular sludge

Sludge volume index

Quantitative image analysis

Multilinear regression

\begin{abstract}
A B S T R A C T
Aerobic granular sludge (AGS) is considered a promising technology for wastewater treatment. Furthermore, it is recognized that the stability of the process is related to the balanced growth of the suspended (floccular) and granular fractions. Therefore, the development of adequate techniques to monitor this balance is of interest. In this work the sludge volume index (SVI), volatile suspended solids (VSS) and total suspended solids (TSS) of mature AGS were successfully predicted with multilinear regression (MLR) models using data obtained from quantitative image analysis (QIA) of both fractions (suspended and granular). Relevant predictions were obtained for the SVI ( $R^{2}$ of 0.975 ), granules TSS ( $R^{2}$ of 0.985$)$, flocs TSS ( $R^{2}$ of 0.971 ), granules VSS ( ${ }^{2}$ of 0.984 ) and flocs VSS ( $\mathrm{R}^{2}$ of 0.986$)$. The estimation of the granular fraction ratio from the predicted TSS and VSS was also successful $\left(\mathrm{R}^{2}\right.$ of 0.985$)$. The predictions help to avoid instability episodes of the AGS system, such as changes in biomass morphology, structure and settling properties.
\end{abstract}

\section{Introduction}

Activated sludge (AS) systems are complex ecosystems mainly constituted by bacteria and protozoa, where bacteria, filamentous or not, are agglomerated as flocs [1]. It is recognized that floc-forming bacteria, such as aerobic heterotrophic (feeding on organic matter) and autotrophic (nitrifying and sulfur oxidizing), as well as denitrifying, sulfate-reducing, and phosphate-accumulating organisms (PAO) are the main organisms responsible for pollution reduction in AS systems. On the other hand, filamentous bacteria are quite relevant in the formation of the flocs' backbone, which is a key feature in terms of the sludge characteristics. An excess of these bacteria may result in filamentous bulking or foaming events, and a shortage of filamentous bacteria in dispersed growth or pinpoint floc formation [2]. Both cases lead to poor sludge characteristics and sedimentation problems in the reactor and secondary clarifier [1-3].

The aerobic granular sludge (AGS) systems are a promising technology to replace AS systems due to the smaller footprint and the possibility to remove organic matter and nutrients ( $\mathrm{N}$ and $\mathrm{P}$ ) simultaneously in the same reactor $[4,5]$. In this sense, AGS systems have already been used to treat different troublesome wastewaters including from the pulp and paper industry, petrochemical, hypersaline, oily and sulfur-laden effluents, and applied in heavy metals removal, among others [6-10]. However, the performance and stability of the biomass aggregates is related to their structure and settling ability [11,12], and it is known that changes in the granules size can occur due to unstable process conditions [13]. More recently, it was found that AGS systems became less stable when high suspended (floccular) biomass fractions occur [14]. Thus, the evaluation of both suspended and granular fractions contents in mature AGS is of major interest, in order to understand

\footnotetext{
Abbreviations: AS, activated sludge; AGS, aerobic granular sludge; $\mathrm{BOD}_{5}$, biochemical oxygen demand; CC, cross correlation; COD, chemical oxygen demand; Deq, equivalent diameter; Ecc, eccentricity; HRT, hydraulic retention time; MLR, multilinear regression; Nb, number of flocs/granules; $\mathrm{NH}_{4}{ }^{+}$, ammonium; $\mathrm{NO}_{2}{ }^{-}$, nitrite; $\mathrm{NO}_{3}{ }^{-}$, nitrate; PAO, polyphosphate accumulating organisms; PLS, partial least square; PCA, principal component analysis; QIA, quantitative image analysis; RMSE, root mean squared error; Rob, robustness; SBR, sequencing batch reactor; SVI, sludge volume index; TIN, total inorganic nitrogen; TP, total phosphorus; TL, total filaments length; TA, total projected area of flocs; TV, total granules volume; TSS, total suspended solids; Vol, volume; VSS, volatile suspended solids; WWTP, wastewater treatment plant

* Corresponding author.

E-mail address: daniela@deb.uminho.pt (D.P. Mesquita).
} 
the correct balance between them and avoid instability problems leading to a decrease in the biomass settling ability.

At present, classic settling ability measurements, e.g., the sludge volume index (SVI) and microscopic examination, merely provide basic information on the extent of instability problems. Therefore, these problems are often detected at an advanced stage, resulting in a large time delay in bulking control decisions as well as reducing the consumption of chemicals [15]. In order to overcome such difficulties, quantitative image analysis (QIA) has become, nowadays, a very important tool to overcome such problems. As main advantages, QIA removes the subjectivity of human analysis, enabling to extract quantitative data and avoid tedious and highly time-consuming tasks to human operators [16]. In fact, QIA has been increasingly used for wastewater treatment plants (WWTP) characterization, since the initial studies of Grijspeerdt and Verstraete in 1997 [17] using QIA to relate the sludge characteristics to the settling ability, also studied by $[15,18-20]$. Nonetheless, most published studies used QIA for the characterization of the structural differences of the aggregated biomass, resulting from different operating conditions, in AS systems rather than AGS systems [16,21-25].

Given the large amount of data provided by QIA the use of a number of different multivariate statistical techniques, such as cross correlation (CC), partial least squares (PLS), and principal components analysis (PCA) render indispensable to organize the data and extract relevant information. In fact such techniques have already been found useful to correlate operational conditions to sludge characteristics and predict biochemical oxygen demand $\left(\mathrm{BOD}_{5}\right)$ and removal of trace organic compounds in WWTP [26-28].

Although QIA techniques have already been successfully applied to monitor anaerobic granular sludge [29-31], to the authors' knowledge, studies regarding the application of QIA to AGS systems are still scarce. Nonetheless, the application of QIA can be a useful tool to characterize, for example, the start-up of AGS systems and the structure of mature AGS, as well as to monitor the balance between suspended and granular fractions. Taking this into consideration, the main objective of this work is to present a QIA based methodology to characterize the structure of suspended and granular fractions of mature AGS [6], and predict their settling ability using multilinear regression (MLR) methods.

\section{Materials and methods}

\subsection{Experimental survey: Reactor set-up}

A $5 \mathrm{~L}$ sequencing batch reactor (SBR) was fed with a synthetic medium [5] containing $1000 \mathrm{mg} \mathrm{COD} \mathrm{L}^{-1}$ with acetate as carbon source, $200 \mathrm{mg} \mathrm{NH}_{4}{ }^{+}-\mathrm{N} \mathrm{L}^{-1}$ and $80 \mathrm{mg} \mathrm{PO}_{4}{ }^{-3}-\mathrm{P} \mathrm{L}^{-1}$. The $6 \mathrm{~h}$ operational cycle encompassed $120 \mathrm{~min}$ of non-aerated feeding, $232 \mathrm{~min}$ of aeration, $3 \mathrm{~min}$ of settling and $5 \mathrm{~min}$ of effluent withdrawal. A $12 \mathrm{~h}$ hydraulic retention time (HRT) was used and the aeration was supplied with $4.79 \mathrm{~L} \mathrm{~min}^{-1}$ of air flow maintaining the dissolved oxygen around $5 \mathrm{mg} \mathrm{O} \mathrm{O}_{2} \mathrm{~L}^{-1}$. The SBR was inoculated with AGS from a Portuguese municipal WWTP and a stabilization period of 66 days was allowed before monitoring took place. The characterization of the mature and stable AGS was then performed once per week for a period of two months, between May and July, under room temperature $\left(23-28^{\circ} \mathrm{C}\right)$.

\subsection{Analytical methods}

Chemical oxygen demand (COD), ammonium $\left(\mathrm{NH}_{4}{ }^{+}\right)$, nitrite $\left(\mathrm{NO}_{2}{ }^{-}\right)$, nitrate $\left(\mathrm{NO}_{3}{ }^{-}\right)$, and total phosphorus (TP) concentrations were determined with Hach Lange cell tests on a Hach Lange DR 5000 spectrophotometer (Hach Lange, Dusseldorf, Germany). The total inorganic nitrogen (TIN) concentration in the influent was assumed to be equal to the ammonium concentration, while the TIN in the effluent was determined as the sum of ammonium, nitrite, and nitrate concentrations. Total and volatile suspended solids (TSS and VSS) and SVI at $5\left(\mathrm{SVI}_{5}\right)$ and $30 \mathrm{~min}\left(\mathrm{SVI}_{30}\right)$ were determined according to standard methods [32]. Additionally, in the case of TSS and VSS, the measurements were performed in the different fractions of the mature AGS:

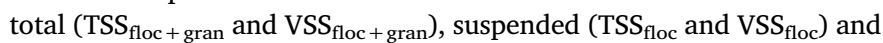
granular $\left(\mathrm{TSS}_{\text {gran }}\right.$ and $\mathrm{VSS}_{\text {gran }}$ ) fractions. The fractionation of granular and suspended mature AGS was performed with a $500 \mu \mathrm{m}$ sieve, and the retained granules were carefully picked up in a vessel by washing with distilled water to minimize changes in the biomass' morphology during the physical handling.

\subsection{Image acquisition, processing and analysis}

For the QIA analysis, a $35 \mathrm{~mL}$ sample aliquot was collected from inside the SBR in the beginning of the aeration phase. Next, the suspended and granular sludge fractions were separated with a $500 \mu \mathrm{m}$ mesh sieve. Regarding the suspended biomass, images were further acquired in bright field microscopy with an Olympus BX51 microscope (Olympus, Shinjuku, Japan) under a total magnification of $40 \times$. For that purpose, $10 \mu \mathrm{L}$ triplicates of air dried preparations were prepared, for representativeness reasons according to [33], resulting in a total of 150 images per sample where filaments and flocs were acquired (acquisition of an average of 11,200 flocs/sample). With respect to the granular biomass, an Olympus SZ 40 stereomicroscope (Olympus, Shinjuku, Japan) was used under a total magnification of $15 \times$. Images from the entire set of granules found in $35 \mathrm{~mL}$ sample aliquots were acquired in a Petri dish, resulting in the acquisition of more than 200 granules per sample.

The suspended biomass fraction was characterized by QIA (Table 1) in terms of the aggregates (flocs) amount, namely total number per sample volume $\left(\mathrm{Nb}_{\text {flocs }} / \mathrm{Vol}\right)$ and total projected area per sample volume $\left(\mathrm{TA}_{\text {flocs }} / \mathrm{Vol}\right)$, size (in equivalent diameter - Deq) and morphology (robustness - Rob, eccentricity - Ecc, among others). Further information regarding the parameters' calculation can be found in Amaral [34]. The total projected area of the aggregated suspended biomass (flocs) was selected to infer these aggregates contents due to the fact that these structures lack the mechanical strength to retain the compression forces under a slide and coverslip mount. Thus, the flocs thickness cannot be individually asserted in such preparations.

The total filaments length per sample volume (TL/Vol), total filaments length per TSS (TL/TSS) and total filaments length per flocs area $\left(\mathrm{TL} / \mathrm{TA}_{\text {floc }}\right)$ ratios were also determined. The usefulness of these parameters has been proven for filamentous bulking diagnose in AS systems [19] and were expected to be useful for the settling ability assessment in AGS systems.

Furthermore, the flocs were divided into three size classes in equivalent diameter: F1 $(<25 \mu \mathrm{m}), \quad$ F2 $\quad(25-250 \mu \mathrm{m})$, and F3 $(>250 \mu \mathrm{m})$. The number (\% Nb) and area percentages (\% Area) of the F1, F2 and F3 fractions were also determined to evaluate the dominant size class. These parameters have already been found adequate for monitoring settling dysfunctions, namely the identification of filamentous bulking, viscous bulking, and pinpoint phenomena in AS systems [33] and were expected to be useful for the settling ability assessment in AGS systems.

In addition, the granular biomass fraction was characterized (Table 1) in terms of the aggregates (granules) amount, namely total granules number per sample volume $\left(\mathrm{Nb}_{\mathrm{gran}} / \mathrm{Vol}\right)$ and total granules predicted volume per sample volume $\left(\mathrm{TV}_{\mathrm{gran}} / \mathrm{Vol}\right)$, size (Deq) and morphology (robustness, eccentricity, among others). The total estimated volume of the granular biomass was selected to infer its contents, considering a three-dimensional ellipsoidal shape with the granules thickness being allocated by their width values.

Again, three size classes were considered based on the Deq: G1 $(<0.25 \mathrm{~mm})$; G2 $(0.25-2.5 \mathrm{~mm})$; and G3 $(>2.5 \mathrm{~mm})$. The number $(\%$ $\mathrm{Nb}$ ) and volume percentages (\% Vol) of the G1, G2 and G3 fractions, were also determined. Since the SVI determination is dependent of the settled sludge volume, the estimation of the different granules class 
Table 1

Main QIA based parameters determined for the suspended (flocs and filaments) and granular biomass fractions.

\begin{tabular}{|c|c|c|c|c|c|}
\hline Parameter & Description & Min & Avg & Max & STD \\
\hline$(\mathrm{Nb} / \mathrm{Vol})_{\text {flocs }}\left(\mathrm{mL}^{-1}\right)$ & Total flocs per sample volume & $4.43 \times 10^{4}$ & $7.94 \times 10^{5}$ & $1.99 \times 10^{6}$ & $5.04 \times 10^{4}$ \\
\hline$(\mathrm{Nb} / \mathrm{Vol})_{\mathrm{F} 1}\left(\mathrm{~mL}^{-1}\right)$ & F1 per sample volume & $3.02 \times 10^{5}$ & $6.18 \times 10^{5}$ & $1.87 \times 10^{6}$ & $5.19 \times 10^{5}$ \\
\hline$(\mathrm{Nb} / \mathrm{Vol})_{\mathrm{F} 2}\left(\mathrm{~mL}^{-1}\right)$ & F2 per sample volume & $6.52 \times 10^{4}$ & $1.75 \times 10^{5}$ & $3.14 \times 10^{5}$ & $8.01 \times 10^{4}$ \\
\hline$(\mathrm{Nb} / \mathrm{Vol})_{\mathrm{F} 3}\left(\mathrm{~mL}^{-1}\right)$ & F3 per sample volume & $6.60 \times 10^{2}$ & $1.77 \times 10^{3}$ & $3.5 \times 10^{3}$ & $9.06 \times 10^{2}$ \\
\hline$(\mathrm{Nb} / \mathrm{Vol})_{\operatorname{gran}}\left(\mathrm{mL}^{-1}\right)$ & Total granules per sample volume & 11.37 & 13.74 & 18.77 & 2.57 \\
\hline$(\mathrm{Nb} / \mathrm{Vol})_{\mathrm{G} 1}\left(\mathrm{~mL}^{-1}\right)$ & G1 granules per sample volume & 0.94 & 1.59 & 2.83 & 0.75 \\
\hline$(\mathrm{Nb} / \mathrm{Vol})_{\mathrm{G} 2}\left(\mathrm{~mL}^{-1}\right)$ & G2 granules per sample volume & 5.49 & 8.03 & 12.06 & 2.30 \\
\hline$(\mathrm{Nb} / \mathrm{Vol})_{\mathrm{G} 3}\left(\mathrm{~mL}^{-1}\right)$ & G3 granules per sample volume & 2.94 & 4.12 & 5.74 & 0.83 \\
\hline$(\mathrm{TA} / \mathrm{Vol})\left(\mathrm{mm}^{2} \mathrm{~mL}^{-1}\right)$ & Total flocs area per sample volume & 805.4 & 1134.1 & 1478.5 & 236.2 \\
\hline$(\mathrm{TA} / \mathrm{Vol})_{\mathrm{F} 1}\left(\mathrm{~mm}^{2} \mathrm{~mL}^{-1}\right)$ & F1 flocs area per sample volume & 45.6 & 76.9 & 195.3 & 49.6 \\
\hline$(\mathrm{TA} / \mathrm{Vol})_{\mathrm{F} 2}\left(\mathrm{~mm}^{2} \mathrm{~mL}^{-1}\right)$ & F2 flocs area per sample volume & 496.6 & 763.56 & 981.2 & 169.8 \\
\hline$(\mathrm{TA} / \mathrm{Vol})_{\mathrm{F} 3}\left(\mathrm{~mm}^{2} \mathrm{~mL}^{-1}\right)$ & F3 flocs area per sample volume & 65.5 & 182.5 & 327.7 & 102.0 \\
\hline$(\mathrm{TV} / \mathrm{Vol})\left(\mathrm{mm}^{3} \mathrm{~mL}^{-1}\right)$ & Total granules volume per sample volume & 297.8 & 383.2 & 471.0 & 59.5 \\
\hline$(\mathrm{TV} / \mathrm{Vol})_{\mathrm{G} 1}\left(\mathrm{~mm}^{3} \mathrm{~mL}^{-1}\right)$ & G1 granules volume per sample volume & $<0.1$ & $<0.1$ & $<0.1$ & $<0.1$ \\
\hline$(\mathrm{TV} / \mathrm{Vol})_{\mathrm{G} 2}\left(\mathrm{~mm}^{3} \mathrm{~mL}^{-1}\right)$ & G2 granules volume per sample volume & 46.1 & 70.4 & 102.5 & 23.0 \\
\hline$(\mathrm{TV} / \mathrm{Vol})_{\mathrm{G} 3}\left(\mathrm{~mm}^{3} \mathrm{~mL}^{-1}\right)$ & G3 granules volume per sample volume & 210.0 & 312.7 & 419.5 & 75.6 \\
\hline $\mathrm{Ecc}_{\text {flocs }}$ & Total flocs eccentricity & 0.018 & 0.544 & 0.709 & 0.221 \\
\hline $\mathrm{Ecc}_{\mathrm{F} 1}$ & F1 flocs eccentricity & 0.497 & 0.566 & 0.662 & 0.054 \\
\hline $\mathrm{Ecc}_{\mathrm{F} 2}$ & F2 flocs eccentricity & 0.715 & 0.753 & 0.774 & 0.018 \\
\hline $\mathrm{Ecc}_{\mathrm{F} 3}$ & F3 flocs eccentricity & 0.638 & 0.751 & 0.821 & 0.057 \\
\hline Ecc gran $_{\text {gran }}$ & Total granules eccentricity & 0.686 & 0.723 & 0.737 & 0.017 \\
\hline $\mathrm{Ecc}_{\mathrm{G} 1}$ & G1 granules eccentricity & 0.755 & 0.860 & 0.914 & 0.052 \\
\hline $\mathrm{Ecc}_{\mathrm{G} 2}$ & G2 granules eccentricity & 0.686 & 0.714 & 0.747 & 0.018 \\
\hline $\operatorname{Ecc}_{\mathrm{G} 3}$ & G3 granules eccentricity & 0.661 & 0.688 & 0.703 & 0.015 \\
\hline $\operatorname{Rob}_{\text {floc }}$ & Total flocs robustness & 0.010 & 0.695 & 0.887 & 0.282 \\
\hline $\operatorname{Rob}_{\mathrm{F} 1}$ & F1 flocs robustness & 0.797 & 0.861 & 0.901 & 0.037 \\
\hline $\operatorname{Rob}_{\mathrm{F} 2}$ & F2 flocs robustness & 0.582 & 0.630 & 0.677 & 0.029 \\
\hline $\operatorname{Rob}_{\mathrm{F} 3}$ & F3 flocs robustness & 0.383 & 0.482 & 0.557 & 0.064 \\
\hline $\operatorname{Rob}_{\text {gran }}$ & Total granules robustness & 0.707 & 0.743 & 0.764 & 0.018 \\
\hline $\operatorname{Rob}_{\mathrm{G} 1}$ & G1 granules robustness & 0.549 & 0.617 & 0.682 & 0.041 \\
\hline $\operatorname{Rob}_{\mathrm{G} 2}$ & G2 granules robustness & 0.685 & 0.752 & 0.773 & 0.029 \\
\hline $\operatorname{Rob}_{\mathrm{G} 3}$ & G3 granules robustness & 0.760 & 0.769 & 0.783 & 0.009 \\
\hline$\% \mathrm{Nb}_{\mathrm{F} 1}$ & Number percentage of F1 flocs & 3.75 & 7.68 & 18.62 & 4.68 \\
\hline$\% \mathrm{Nb}_{\mathrm{F} 2}$ & Number percentage of F2 flocs & 6.22 & 26.24 & 43.34 & 12.84 \\
\hline$\% \mathrm{Nb}_{\mathrm{F} 3}$ & Number percentage of F3 flocs & 0.055 & 0.299 & 0.726 & 0.220 \\
\hline$\% \mathrm{Nb}_{\mathrm{G} 1}$ & Number percentage of G1 granules & 7.68 & 11.16 & 16.06 & 3.23 \\
\hline$\% \mathrm{Nb}_{\mathrm{G} 2}$ & Number percentage of G2 granules & 46.88 & 57.74 & 66.15 & 7.18 \\
\hline$\% \mathrm{Nb}_{\mathrm{G} 3}$ & Number percentage of G3 granules & 17.79 & 31.10 & 44.87 & 9.00 \\
\hline$\%$ Area $_{\mathrm{F} 1}$ & Area percentage of $\mathrm{F} 1$ flocs & 3.75 & 7.68 & 18.62 & 4.68 \\
\hline$\%$ Area 2 & Area percentage of F2 flocs & 69.94 & 74.80 & 85.21 & 5.55 \\
\hline$\%$ Area $_{\mathrm{F} 3}$ & Area percentage of F3 flocs & 7.03 & 17.52 & 25.44 & 7.62 \\
\hline$\%$ Area $_{\mathrm{G} 1}$ & Area percentage of G1 granules & 0.06 & 0.10 & 0.22 & 0.06 \\
\hline$\%$ Area $_{\mathrm{G} 2}$ & Area percentage of G2 granules & 18.45 & 29.54 & 46.76 & 10.41 \\
\hline$\%$ Area $_{\mathrm{G} 3}$ & Area percentage of G3 granules & 53.02 & 70.36 & 81.49 & 10.46 \\
\hline$\% \mathrm{Vol}_{\mathrm{G} 1}$ & Volume percentage of G1 granules & $<0.01$ & 0.01 & 0.02 & $<0.01$ \\
\hline$\% \mathrm{Vol}_{\mathrm{G} 2}$ & Volume percentage of G2 granules & 10.43 & 19.31 & 32.05 & 8.44 \\
\hline$\% \mathrm{Vol}_{\mathrm{G} 3}$ & Volume percentage of G3 granules & 67.94 & 80.69 & 89.57 & 8.45 \\
\hline $\mathrm{TL} / \mathrm{Vol}\left(\mathrm{mm} \mathrm{mL}^{-1}\right)$ & Total filaments length per total sample volume & 822.7 & 2766.1 & 4638.7 & 1460.5 \\
\hline $\mathrm{TL} / \mathrm{TA}_{\mathrm{floc}}\left(\mathrm{mm} \mathrm{mm}^{-2}\right)$ & Total filaments length per total area of flocs & 0.726 & 2.393 & 4.048 & 1.103 \\
\hline $\mathrm{TL} / \mathrm{TSS}\left(\mathrm{mm} \mathrm{mg}^{-1}\right)$ & Total filaments length per total suspended solids & 0.124 & 0.476 & 0.883 & 0.279 \\
\hline
\end{tabular}

Min: Minimum; Avg: Average; Max: Maximum; STD: Standard deviation.

volume was expected to be useful for the settling ability assessment in AGS systems.

The performed size overlapping between the larger flocs and smaller granules classes allowed accounting for suspended biomass possibly trapped in the sieve, though presenting a diameter smaller than $500 \mu \mathrm{m}$ and granular biomass smaller than $500 \mu \mathrm{m}$. The main QIA based parameters determined for both biomass fractions are presented in Table 1.

All QIA programs used for the characterization of the suspended (flocs and filaments) and granular sludge were developed in-house in Matlab 7.3 (The Mathworks, Inc., Natick, USA), adapting a previous version developed by Amaral [34]. A more detailed description of the determined morphological parameters can be found in Amaral [34].

\subsection{Multilinear regression analysis}

The MLR analysis is a linear regression method for estimating dependent variables ( $\mathrm{Y}$ data) from a set of explanatory variables ( $\mathrm{X}$ data).
The MLR calculates the explanatory variables coefficients $(\beta)$ by minimizing the sum of the residuals (differences between observed and predicted Y values) squares in a given dataset. An MLR model can be represented by the following equation:

$Y=\beta_{0}+\sum \beta_{i} x_{i}+\varepsilon$

where $x_{i}$ represents an explanatory variable of $Y$ (the dependent variable), $\beta_{i}$ is the coefficient associated to the explanatory variable $x_{i}$, and $\varepsilon$ is the residual [28].

In the current study, the MLR methodology was employed to obtain linear model fits for TSS and VSS (both for the suspended and granular biomass) and $\mathrm{SVI}_{30}$ (Y data) from the QIA based dataset (X data). Care was taken not to overfit the obtained models to the (limited) number of samples used. For that purpose, the maximum number of parameters allowed for each model was set to three. An iterative process was used by running the MLR on all the parameters capable of influencing each parameter and selecting in sequence the parameters that influenced the most. Furthermore, solely the models and explanatory variables 

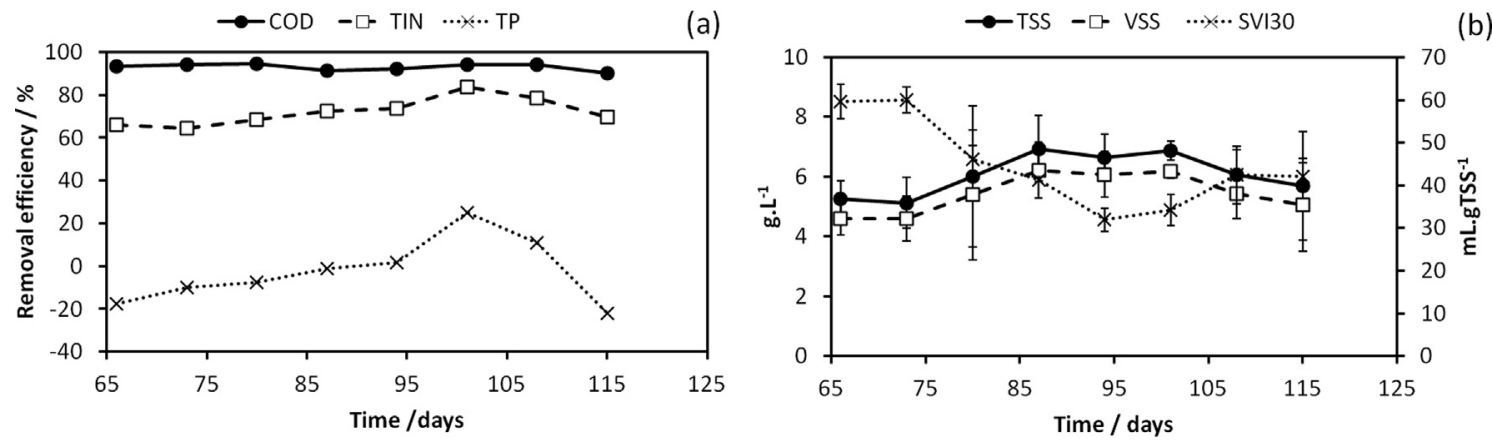

Fig. 1. Performance of the reactor throughout the monitoring period for (a) COD, TIN and TP removal efficiencies; (b) biomass concentrations (SSV and TSS) and settling characteristics.

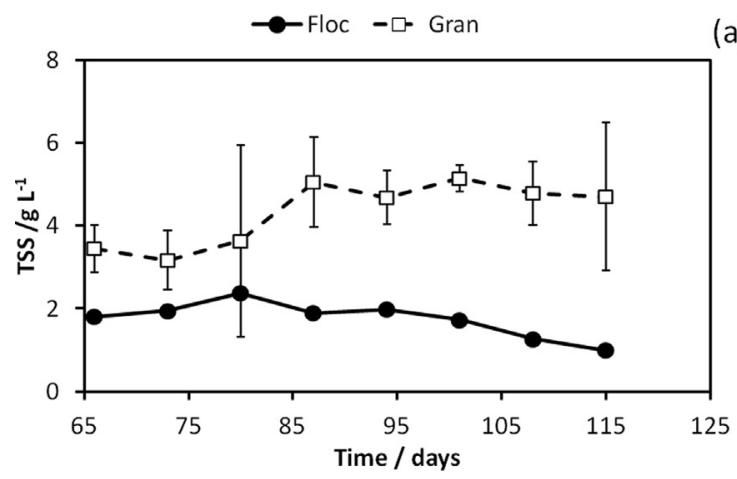

(a)

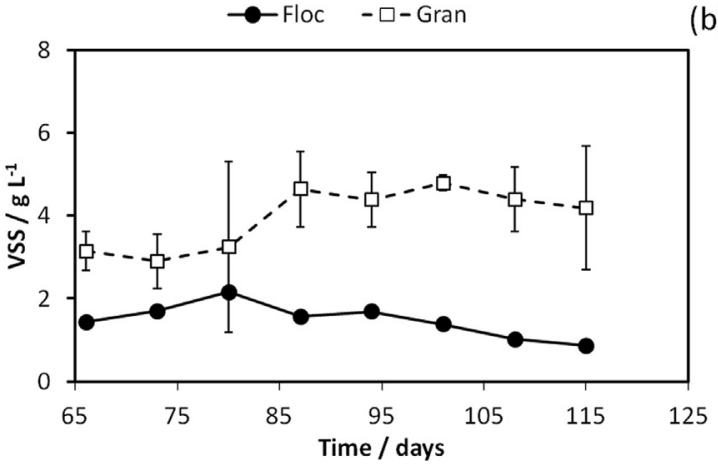

(b)

Fig. 2. (a) TSS and (b) VSS evolution for the suspended (Floc) and granular (Gran) biomass.

(including the intercept) with coefficients presenting a probability value (p-value) below 0.01 , that is, statistically significant for a level of significance $(\alpha)$ of 0.01 , were taken into account.

All of the above MLR analyses were performed in Matlab 7.3 (The Mathworks, Inc. Natick, USA).

\section{Results and discussion}

\subsection{SBR performance with stable and mature AGS}

The performance of the reactor, assessed by the COD, TIN, and TP removal efficiencies (Fig. 1a), and the biomass concentrations (TSS and VSS) and settling characteristics (Fig. 1b), throughout the monitoring period, are presented in Fig. 1.

The SBR performance, in the period upon obtaining mature AGS (days 66-115), showed high and relatively constant removal efficiencies (Fig. 1a) regarding the COD (above $90 \%$, with an average value of $93 \pm 2 \%$ ) and ammonia oxidation (above $90 \%$, with an average value of $94 \pm 2 \%$ - data not shown). In addition, during the entire operational period, the TIN removal efficiency remained somewhat constant with an average value of $72 \pm 7 \%$. On the other hand, the TP removal efficiency remained, for the most part of the monitoring period, quite low or even negative. The negative TP removal efficiency could be related to the interference of nitrates on PAO metabolism. Nitrate can inhibit phosphorus release in anaerobic conditions and uptake in the aerobic ones [35]. Several references can be found in literature reporting similar results of COD and TIN removal efficiencies in lab scale, pilot scale, and full scale AGS systems, respectively [36-39]. Moreover, also poor TP removal efficiencies (around 15\%) were achieved in the first days of operation of a lab scale AGS system under high temperature [40], comparatively to higher TP removal efficiencies encompassing pilot scale (>90\%) and full scale (90\%) operation $[37,38]$.

Regarding the biomass physical characteristics (Fig. 1b), the $\mathrm{SVI}_{30}$ varied between 32 and $60 \mathrm{~mL} \mathrm{gTSS}^{-1}$, indicating an AGS with a good settling ability, presenting an $\mathrm{SVI}_{5} / \mathrm{SVI}_{30}$ ratio very close to 1 (average value of $1.05 \pm 0.04$ ). Although the $\mathrm{SVI}_{30}$ decreased in the first part of the monitoring period, from the day 80 onwards remained somewhat stable (average value of $38.7 \pm 6.0 \mathrm{~mL} \mathrm{gTSS}^{-1}$ ). The obtained values can be considered in accordance with several references found in the literature regarding the expected SVI of stable and mature AGS $[38,41]$.

The VSS concentration inside the SBR varied between 4.6 and $6.2 \mathrm{~g}$ VSS $\mathrm{L}^{-1}$ (average value of $6.1 \pm 0.7 \mathrm{~g} \mathrm{VSS} \mathrm{L}^{-1}$ ) whereas the TSS varied between 5.1 and $6.9 \mathrm{~g} \mathrm{TSS}^{-1}$ (average value of $5.4 \pm 0.7 \mathrm{~g}$ TSS $\mathrm{L}^{-1}$ ), reflecting a VSS/TSS average ratio of $0.89 \pm 0.01$. These values reflected the last stages of the dynamic granules' maturation process in the current experiment. Given the synthetic feed used in this experiment it was possible to obtain such large VSS/TSS values and, according to the literature, even larger values could be obtained depending on a number of operational parameters [6].

\subsection{Suspended and granular fractions structure}

Fig. 2 presents the evolution of the entire sample (total), suspended, and granular biomass fractions throughout the monitoring period. Regarding the suspended solids (TSS and VSS) (Fig. 2a, b), the granular biomass fraction predominated throughout the monitoring period, presenting an average value of $4.3 \pm 0.8 \mathrm{~g} \mathrm{TSS} \mathrm{L}^{-1}$ and $4.0 \pm 0.7 \mathrm{~g}$ VSS $\mathrm{L}^{-1}$, around two and a half times larger than the suspended biomass fraction counterpart (with average values of $1.7 \pm 0.4 \mathrm{~g} \mathrm{TSS} \mathrm{L}^{-1}$ and $1.5 \pm 0.4 \mathrm{~g} \mathrm{VSS}^{-1}$ ). Furthermore, a shift towards an increased content in granular biomass (both in terms of TSS and VSS) occurred from day 80 to day 87 , and from that day onwards the granular biomass solids concentration remained stable (average values of $4.9 \pm 0.2 \mathrm{~g}$ TSS $\mathrm{L}^{-1}$ and $4.5 \pm 0.2 \mathrm{~g} \mathrm{VSS} \mathrm{L}^{-1}$, respectively). On the other hand, from day 80 onwards, both the TSS and VSS concentrations of the suspended biomass steadily decreased until the end of the monitoring period (1.0 $\mathrm{g} \mathrm{TSS} \mathrm{L}^{-1}$ and $0.9 \mathrm{~g} \mathrm{VSS} \mathrm{L}^{-1}$ in the last day of the monitoring period).

The evolution of the $\mathrm{TA}_{\text {flocs }} / \mathrm{Vol}$ and \% Area for the F1, F2 and F3 

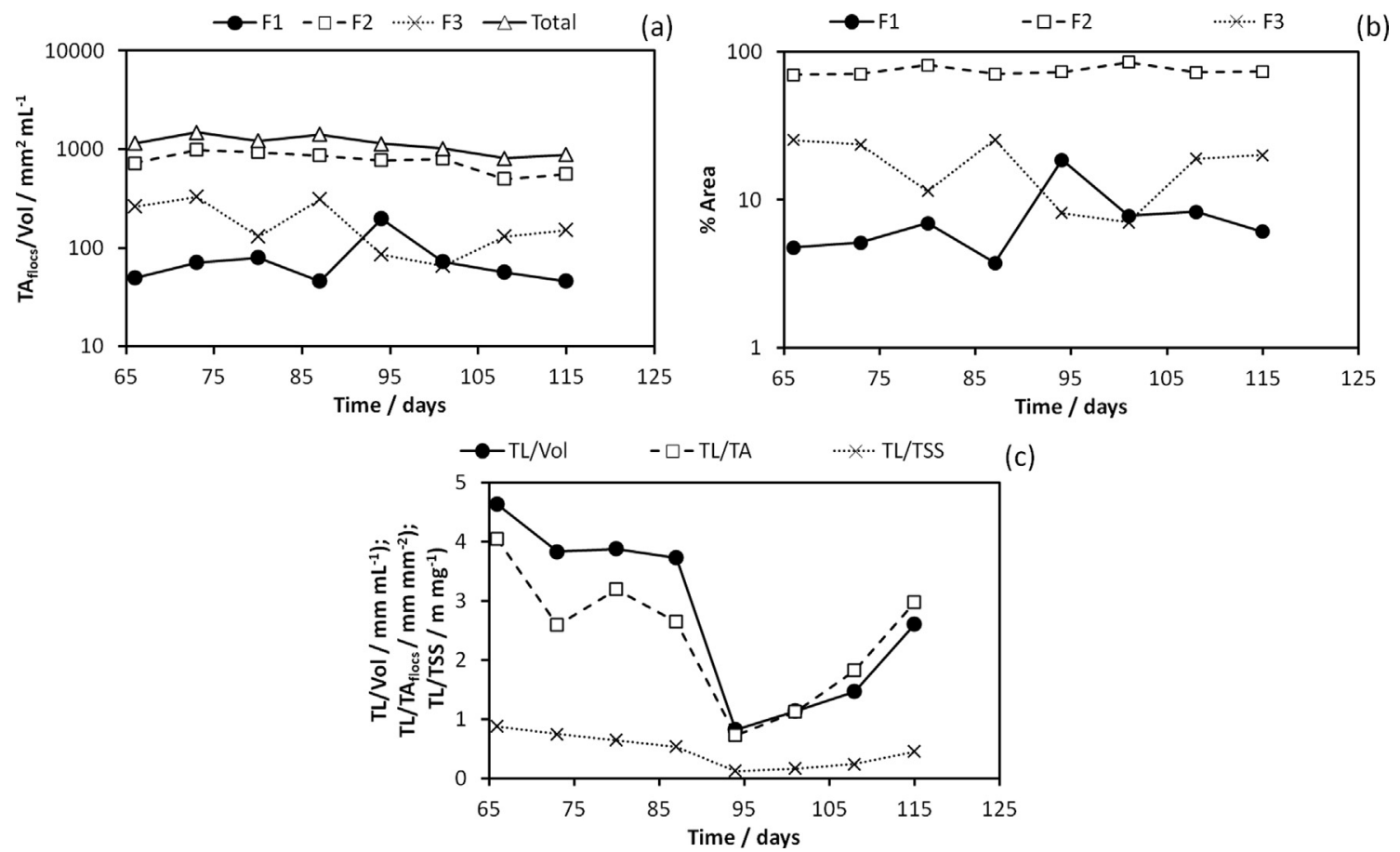

(c)

Fig. 3. Evolution of the (a) $\mathrm{TA}_{\mathrm{flocs}} / \mathrm{Vol}$ and (b) \% Area for the F1, F2 and F3 fractions; (c) TL/TA flocs, TL/TSS and TL/Vol ratios.

fractions, and of the $\mathrm{TL} / \mathrm{TA}_{\text {flocs}}$, TL/TSS and $\mathrm{TL} / \mathrm{Vol}$ ratios throughout the monitoring period are presented in Fig. 3. The suspended aggregated (flocs) biomass amount (Fig. 3a), in terms of projected area per sample volume, steadily decreased from day $87\left(1408 \mathrm{~mm}^{2} \mathrm{~mL}^{-1}\right)$ onwards ( $876 \mathrm{~mm}^{2} \mathrm{~mL}^{-1}$ in the last day of the monitoring period), in line with the flocs TSS and VSS decrease. Within the flocs biomass, the intermediate (F2, $25-250 \mu \mathrm{m})$ flocs predominated $(70 \%$ or above with an average of $74.8 \pm 5.6 \%$ ) throughout the entire monitoring period, followed by the larger $(\mathrm{F} 3,>250 \mu \mathrm{m})$ flocs (average value of $17.5 \pm 7.6 \%)$. On the other hand, the smaller $(\mathrm{F} 1,<25 \mu \mathrm{m})$ flocs (average value of $7.7 \pm 4.7 \%$ ) did not surpass, except from one occasion, the $10 \%$ barrier (Fig. 3b).

Regarding the filamentous contents in the samples (Fig. 3c), and although a significant variation in relative terms was determined (average value of $2.8 \pm 1.5 \mathrm{~m} \mathrm{~mL}^{-1}$ for TL/Vol, $2.4 \pm 1.1 \mathrm{~mm} \mathrm{~mm}^{-2}$ for $\mathrm{TL} / \mathrm{TA}_{\text {flocs }}$ and $0.48 \pm 0.28 \mathrm{~m} \mathrm{mg}^{-1}$ for TL/TSS), in absolute terms the obtained values were found to be quite lower than the filaments threshold able to lead to filamentous bulking problems $\left(20 \mathrm{~m} \mathrm{~mL}^{-1}\right.$ for $\mathrm{TL} / \mathrm{Vol}, 15 \mathrm{~mm} \mathrm{~mm}^{-2}$ for TL/TA flocs and $7 \mathrm{~m} \mathrm{mg}^{-1}$ for TL/TSS [42]).

The evolution throughout the monitoring period, of the $\mathrm{TV}_{\text {gran }} / \mathrm{Vol}$ and \% Vol for the G1, G2 and G3 fractions is presented in Fig. 4. The granular biomass amount, in terms of estimated volume per sample volume (average value of $383 \pm 59 \mathrm{~mm}^{3} \mathrm{~mL}^{-1}$ ), slightly oscillated during the monitoring period (Fig. 4a). Within the granular biomass, the larger granules $(\mathrm{G} 3,>2.5 \mathrm{~mm}$ ) predominated $(68 \%$ or above with an average value of $80.7 \pm 8.4 \%$ ) throughout the entire monitoring period (Fig. 4b), followed by the intermediate (G2, $0.25-2.5 \mathrm{~mm}$ ) granules (average value of $19.3 \pm 8.4 \%$ ). On the other hand, the smaller (G1, $<0.25 \mathrm{~mm}$ ) granules (average of $0.006 \pm 0.004 \%$ ) could be considered almost negligible. Furthermore, with the increased solids concentration in granular biomass (TSS and VSS) that occurred from day 80 to day 87 , the smaller granules practically disappeared.

Fig. 5 presents the evolution of the robustness and eccentricity morphological descriptors for the F1, F2, F3, G1, G2 and G3 fractions throughout the monitoring period.

The evolution of the overall aggregated (flocs) biomass morphology (in terms of robustness and eccentricity) was found to be quite dependent on the smaller flocs due to the fact that this fraction was highly predominant in terms of their numbers (above $73 \%$ in average) (Fig. 5a). And, although the intermediate flocs (predominant in terms of projected area) presented a somewhat stable morphology (robustness average value of $0.63 \pm 0.03$ and eccentricity of $0.75 \pm 0.02$ ) throughout the monitoring period, an overall decreasing trend in the aggregates robustness (Fig. 5a) and increasing trend in their eccentricity (Fig. 5c), representative of the flocs deterioration, could be found from day 87 onwards.
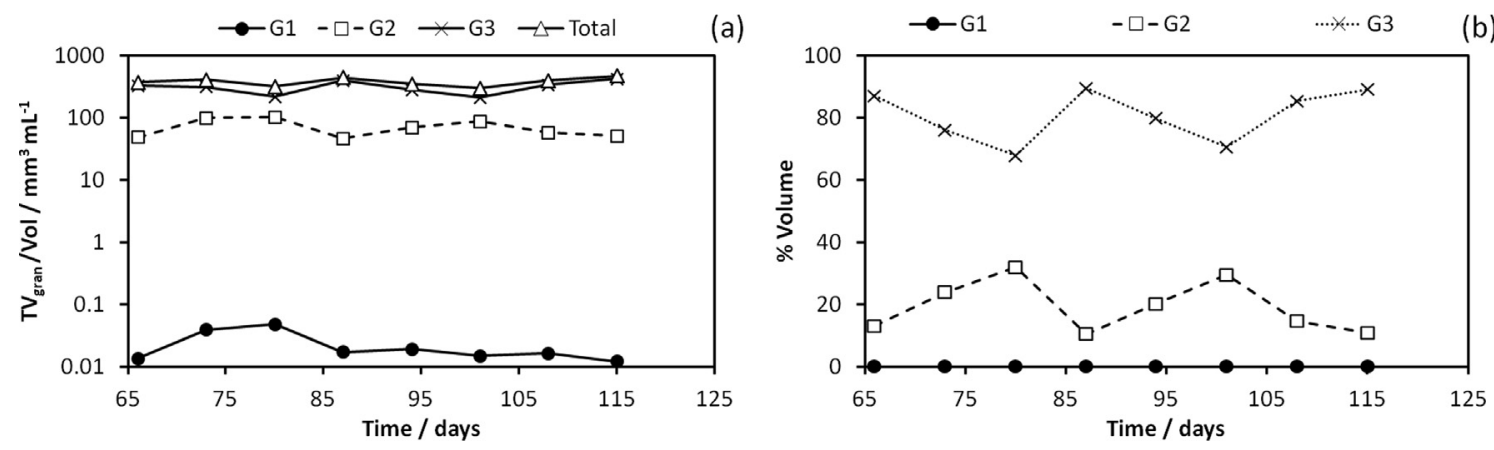

Fig. 4. Evolution of (a) $\mathrm{TV}_{\mathrm{gran}} / \mathrm{Vol}$ and (b) \% Vol for the G1, G2 and G3 fractions. 


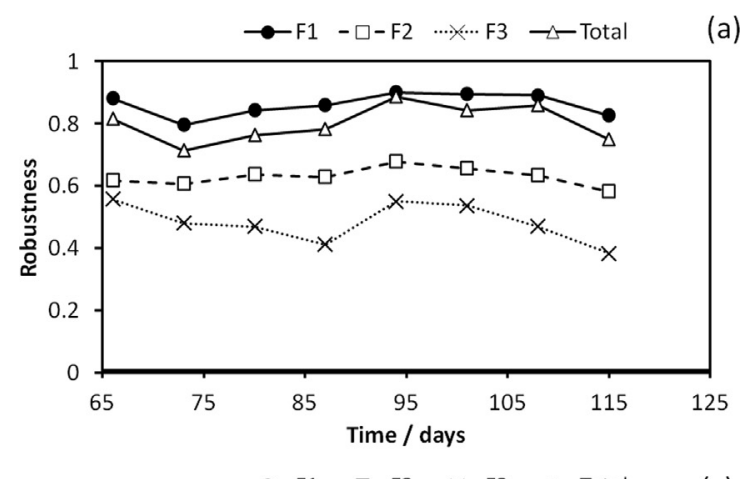

(a)
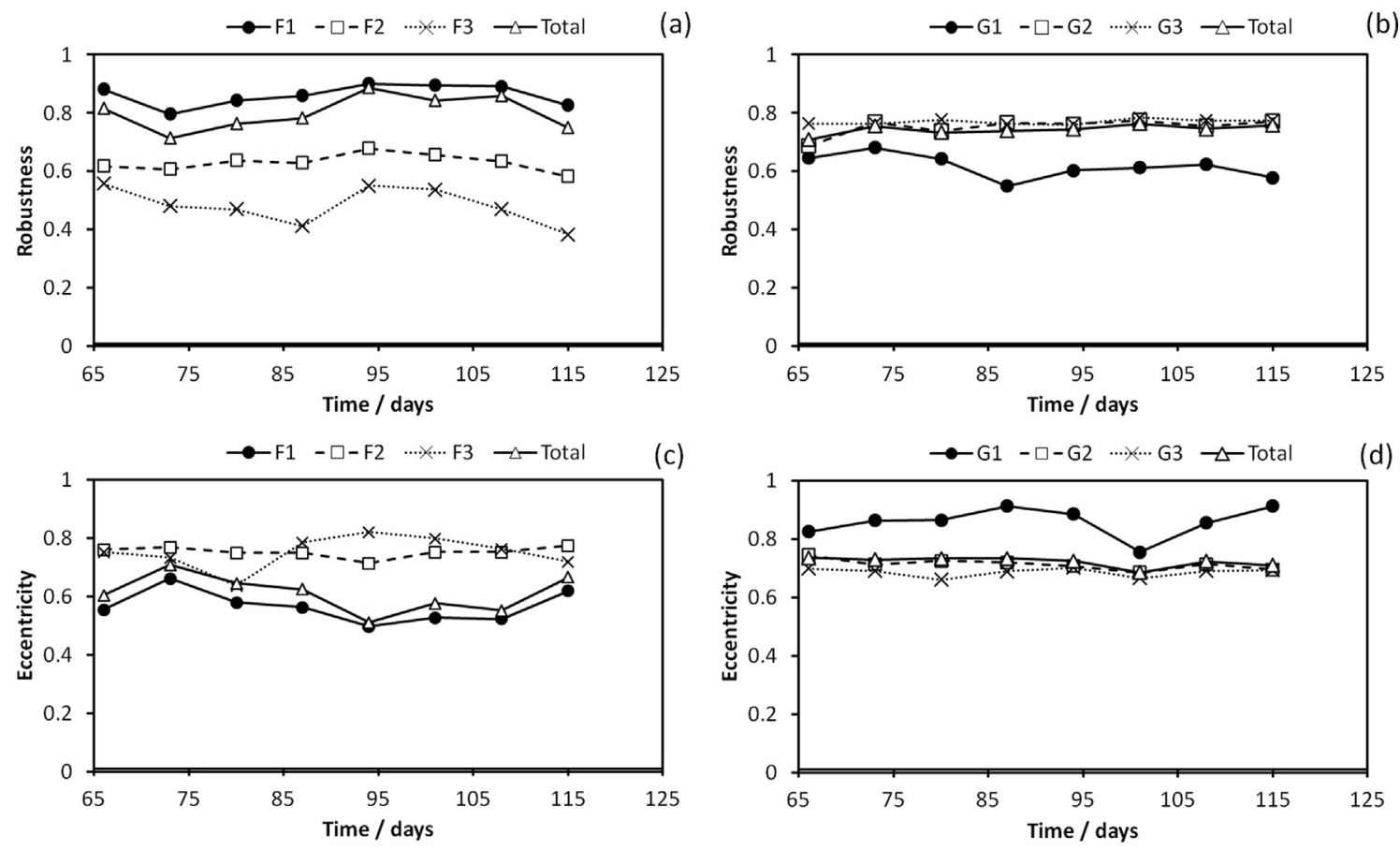

Fig. 5. Evolution of the robustness for (a) F1, F2, F3 fractions, (b) G1, G2, G3 fractions and eccentricity, for (c) F1, F2, F3 fractions, (d) G1, G2, G3 fractions.

Regarding the granular biomass, the obtained $0.74 \pm 0.02$ overall values for the robustness (Fig. 5b) and $0.72 \pm 0.02$ for the eccentricity (Fig. 5d), indicate the presence of robust, yet slightly elongated, structures. Furthermore, both the overwhelming intermediate and larger granular biomass morphology was found to be quite stable during the entire monitoring period.

\subsection{TSS and VSS prediction for suspended and granular fractions}

The prediction of VSS, TSS, and $\mathrm{SVI}_{30}$ was performed by the MLR technique taking into consideration the physical, chemical, and morphological parameters (filamentous, suspended and granular biomass) obtained. Furthermore, while $\mathrm{SVI}_{30}$ was predicted assuming both suspended and granular fractions together, the VSS and TSS were predicted for separated fractions, and are presented in Fig. $6 \mathrm{a}-\mathrm{b}$ and $\mathrm{c}-\mathrm{d}$ for the suspended and Fig. 7a-b and c-d for the granular fractions, respectively. In spite the fact that, in AGS systems, both granular and suspended fractions appear together, the stability of the system is dependent on the balance between the suspended and granular fractions, thus, the predictions of VSS and TSS were accomplished separately for both fractions.

With respect to the VSS of the suspended fraction, a coefficient of determination $\left(R^{2}\right)$ of 0.986 , (with $p$-value $<0.01$ and root mean square error - RMSE of 0.06 ) was obtained for the prediction model showed in Eq. (2), based on the overall flocs contents (TA/Vol), the robustness of the intermediate flocs and the eccentricity of the larger flocs. As could be expected, the flocs VSS is directly dependent on the overall suspended biomass aggregates area and on the robustness of the predominant intermediate flocs, and inversely dependent on the aggregates eccentricity, in terms of the (second predominant) larger flocs.

$\mathrm{VSS}_{\text {floc }}$

$$
=-2.832+10.935\left(\operatorname{Rob}_{\mathrm{F} 2}\right)-4.638\left(\mathrm{Ecc}_{\mathrm{F} 3}\right)+1.096 \times 10^{-3}(\mathrm{TA} / \mathrm{Vol})
$$

Regarding the TSS of the suspended fraction, a 0.971 coefficient of determination (p-value $<0.01$ and RMSE of 0.10 ) was obtained for the prediction model presented in Eq. (3), based on the intermediate flocs contents $\left(\mathrm{TA} / \mathrm{Vol}_{\mathrm{F} 2}\right)$ and the eccentricity of the larger and overall flocs.
As could be expected, the flocs TSS is directly dependent on the suspended biomass aggregates area, in terms of the predominant intermediate flocs, and inversely dependent on the aggregates eccentricity, both overall and in terms of the larger flocs.

$\mathrm{TSS}_{\text {floc }}=4.762+2.68 \times 10^{-3}\left(\mathrm{TA} / \mathrm{Vol}_{\mathrm{F} 2}\right)-4.437\left(\mathrm{Ecc}_{\mathrm{Total}}\right)-3.123\left(\mathrm{Ecc}_{\mathrm{F} 3}\right)$

Regarding the VSS prediction for the granular biomass, a 0.984 coefficient of determination (p-value $<0.01$ and RMSE of 0.123) was obtained for the prediction model showed in Eq. (4), based on the intermediate and larger granules contents (TV/Vol), and the robustness of the intermediate granules. As could be expected, the granules VSS is directly dependent on the (intermediate) granules robustness. However, it was also found that the granules VSS was inversely dependent on the (intermediate and larger) granules contents. This result may point to less denser granules as they increase in size.

$\mathrm{VSS}_{\text {gran }}=-7.765+24.6\left(\operatorname{Rob}_{\mathrm{G} 2}\right)-0.048\left(\mathrm{TV} / \mathrm{Vol}_{\mathrm{G} 2}\right)-0.011\left(\mathrm{TV} / \mathrm{Vol}_{\mathrm{G} 3}\right)$

With respect to the granules TSS, a 0.985 coefficient of determination (p-value $<0.01$ and RMSE of 0.13 ) was obtained for the prediction model presented in Eq. (5), based on the volumetric granular biomass distribution for larger granules $\left(\% \mathrm{Vol}_{\mathrm{G} 3}\right)$, and intermediate granules contents $\left(\mathrm{TV} / \mathrm{Vol}_{\mathrm{G} 2}\right.$ ) and robustness. Likewise, to the VSS counterpart, the granules TSS is directly dependent on the (intermediate) granules robustness. However, it was again found that the granules VSS was inversely dependent on the intermediate (TV/ $\mathrm{Vol}_{\mathrm{G} 2}$ ) and larger $\left(\% \mathrm{Vol}_{\mathrm{G} 3}\right)$ granules contents, thus pointing to less denser granules as they increase in size.

$\mathrm{TSS}_{\text {gran }}=7.599+22.25\left(\mathrm{Rob}_{\mathrm{G} 2}\right)-0.082\left(\mathrm{TV} / \mathrm{Vol}_{\mathrm{G} 2}\right)-0.176(\% \mathrm{VolG} 3)$

\subsection{Granular fraction ratio}

The granular fraction ratio, in terms of TSS and VSS, can be estimated by the predicted TSS and VSS of the granular and suspended biomass (Fig. 8). With respect to the obtained TSS granular fraction 
(a)

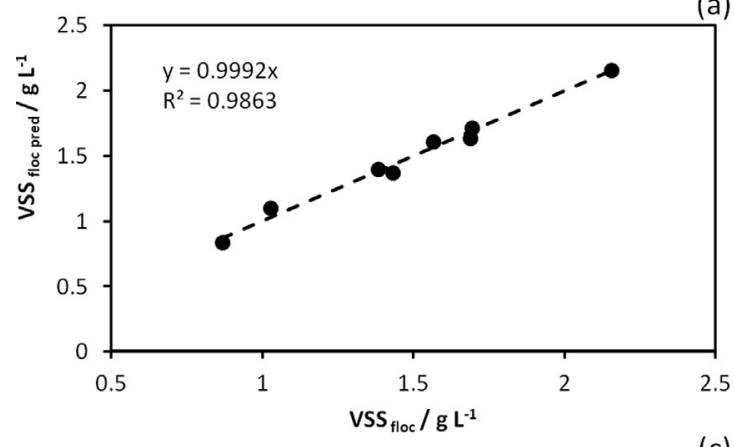

(c)

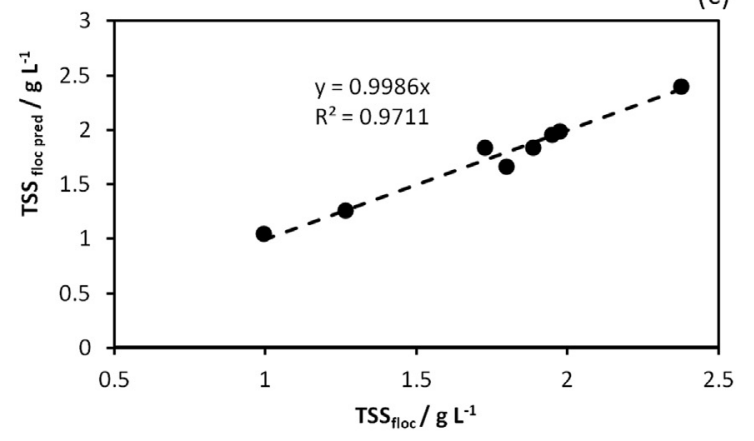

(b)
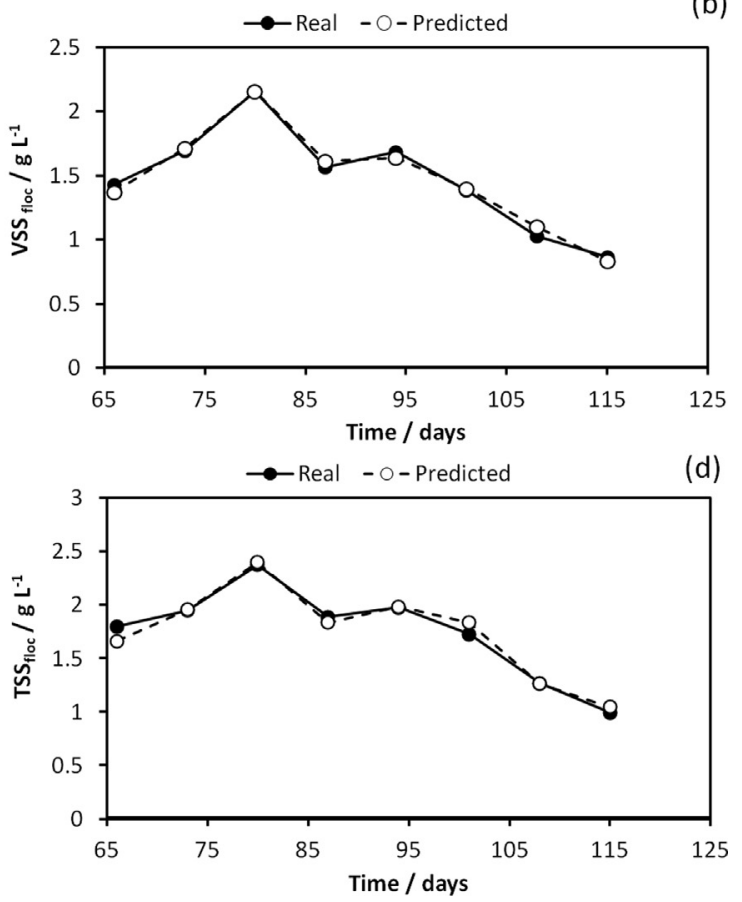

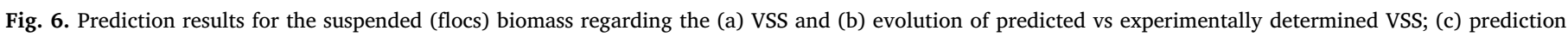
regarding the TSS, and (d) evolution of predicted vs experimentally determined TSS.

ratio estimation (Fig. 8a-b), a 0.985 coefficient of determination (RMSE of 0.87 ) was obtained based on the predicted granular and suspended TSS. Regarding the obtained VSS granular fraction ratio estimation (Fig. 8c-d), a 0.985 coefficient of determination (RMSE of 0.93) was obtained based on the predicted granular and suspended VSS.

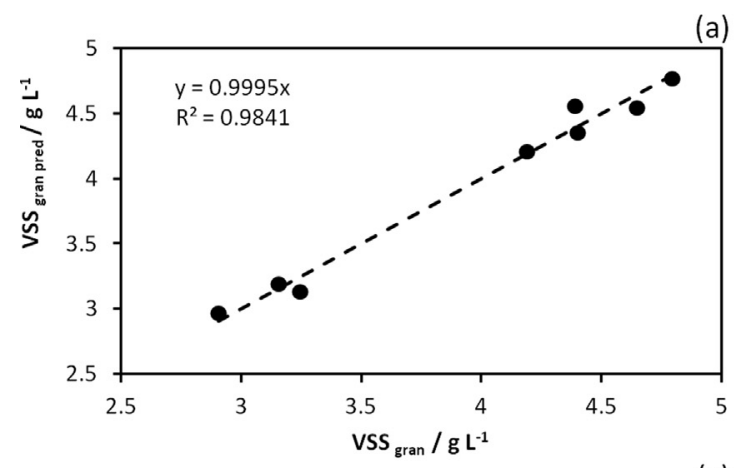

(c)

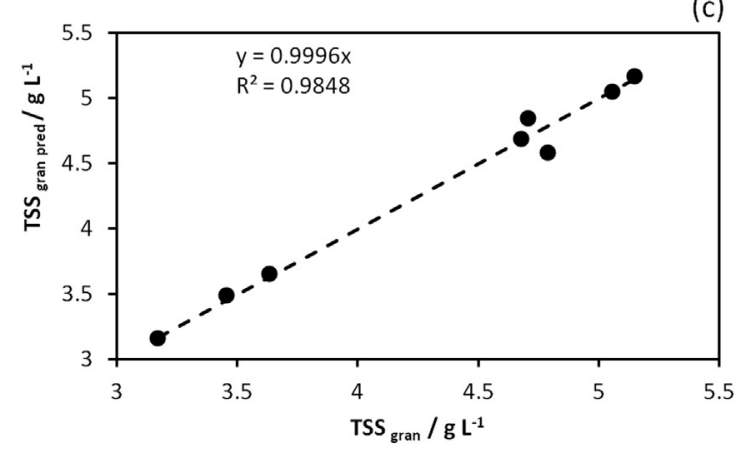

\subsection{Settling ability prediction for aerobic granular sludge}

With respect to the obtained $\mathrm{SVI}_{30}$ prediction model (Fig. 9a-b), presented in Eq. (6), a 0.975 coefficient of determination (p-value < 0.01 and RMSE of 2.24) was obtained based on the granular TSS and area percentage of the larger flocs ( $\left.\% \mathrm{Area}_{\mathrm{F} 3}\right)$. As could be expected, the $\mathrm{SVI}_{30}$ is inversely dependent on the (predominant) granular TSS, since it is a parameter normalized by the biomass contents. Furthermore, the
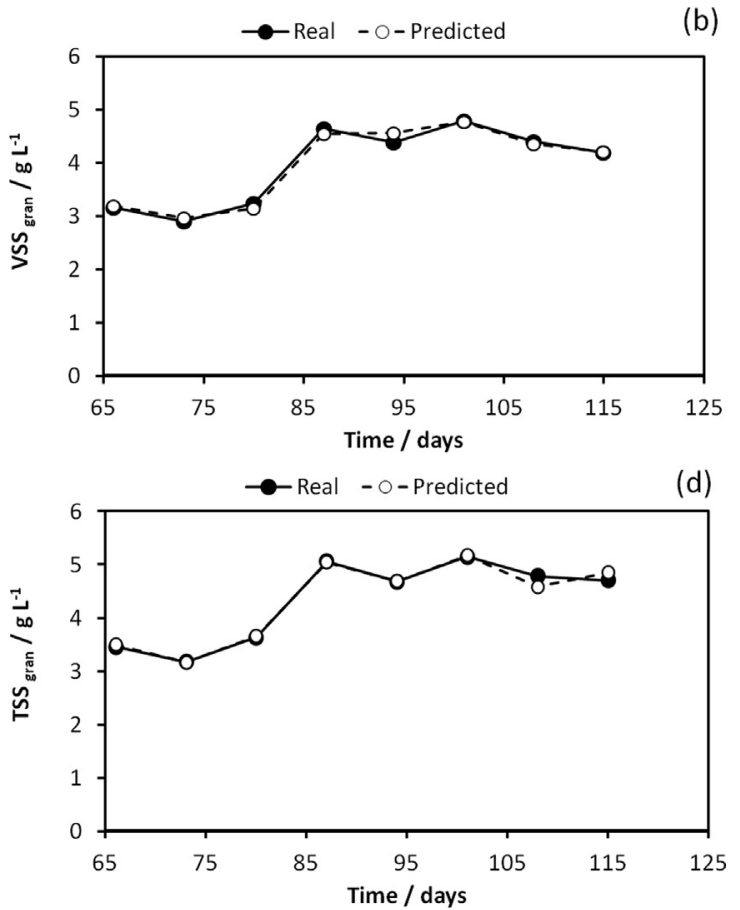

Fig. 7. Prediction results for the granular biomass regarding the (a) VSS and (b) evolution of predicted vs experimentally determined VSS; (c) prediction regarding the TSS and (d) Evolution of predicted vs experimentally determined TSS. 
(a)
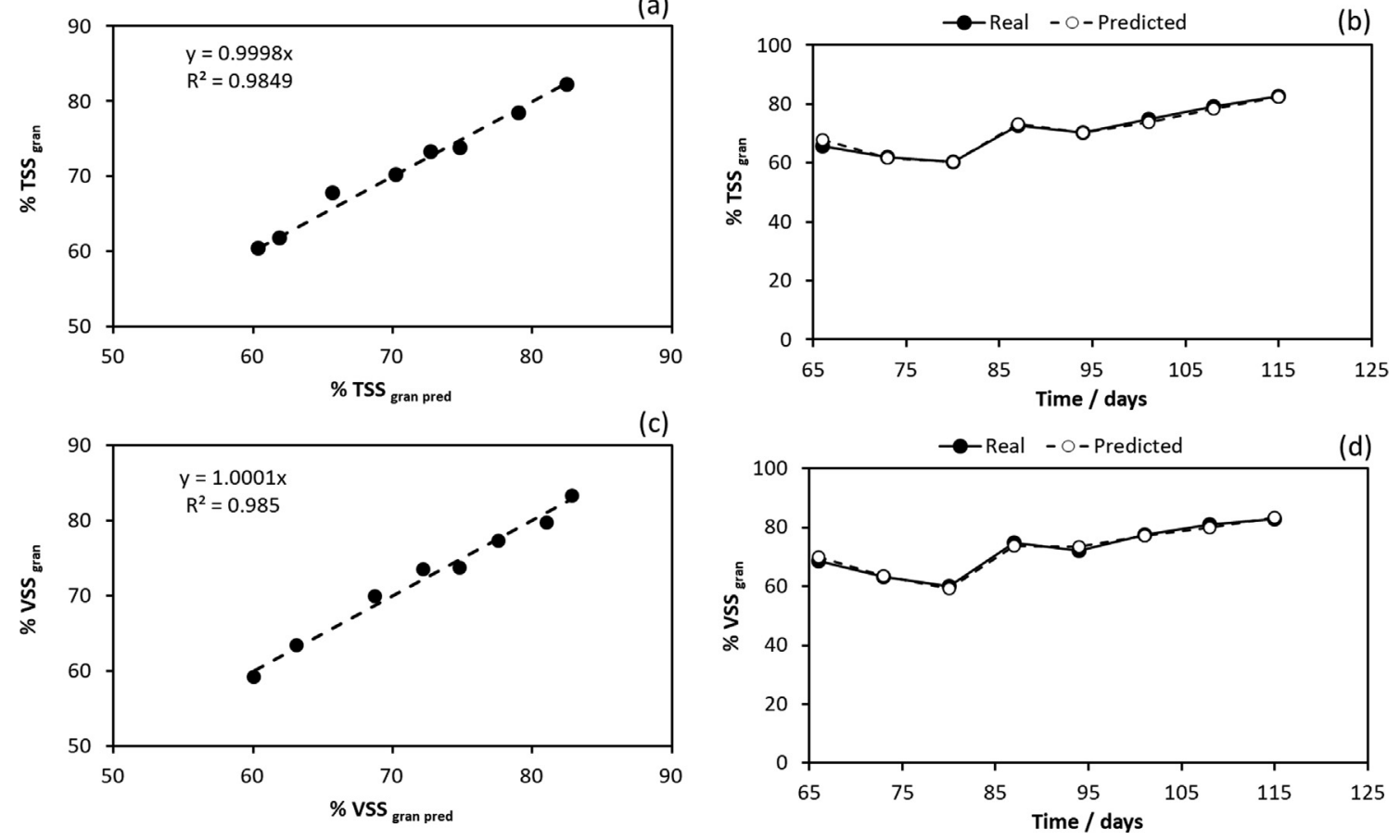

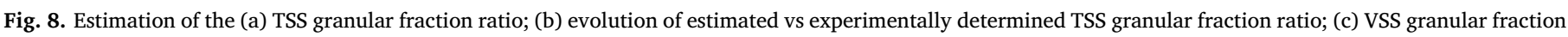
ratio, and (d) evolution of estimated vs experimentally determined VSS granular fraction ratio.

(a)

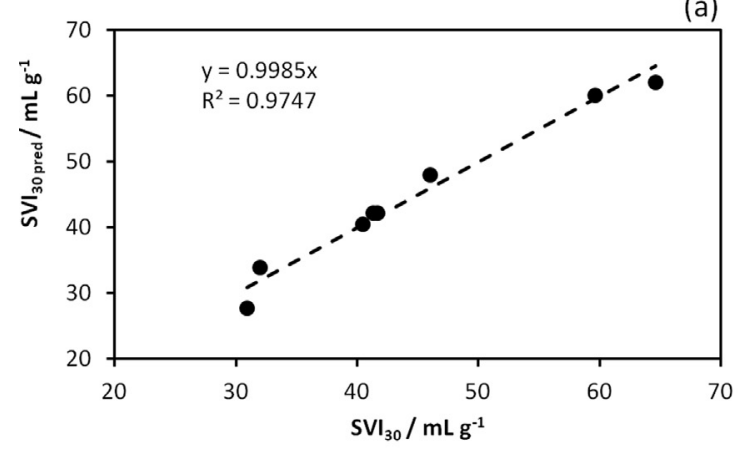

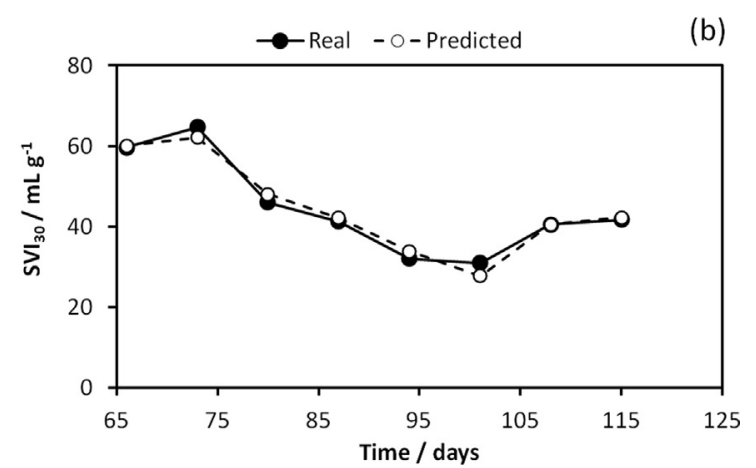

Fig. 9. Prediction results for the (a) $\mathrm{SVI}_{30}$ and (b) evolution of predicted vs experimentally determined $\mathrm{SVI}_{30}$.

fact that the $\mathrm{SVI}_{30}$ is found to be directly dependent on the aggregates distribution in larger flocs may point to a good setting ability of these aggregates.

$\mathrm{SVI}_{30}=80.619-11.265\left(\mathrm{TSS}_{\mathrm{gran}}\right)+0.726\left(\% \mathrm{Area}_{\mathrm{F} 3}\right)$

\subsection{Applicability}

The application of QIA for sludge characterization is based on the use of a microscopy survey of the collected samples, coupled to image acquisition and processing stages. In the current research work, the use of this methodology, coupled with chemometric tools for the solids and sludge volume index estimation in AGS, took around $4 \mathrm{~h}$ of man-work (in average) encompassing the sample collection and preparation, image acquisition and processing, and further extraction and treatment of the quantitative data. Thus, the application of such models can reduce the time of analysis when compared to traditional methods for VSS and TSS (reaching a constant dry weight usually takes quite longer than the $4 \mathrm{~h}$ of the presented methodology), and SVI determination (dependent on the TSS determination), contributing to the process optimization. In this sense, the proposed QIA methodology could be considered a valuable tool, in a daily basis operation, of full scale WWTP monitoring, for timely diagnosis of dysfunctions related to biomass' morphological features.

\section{Conclusions}

AGS processes stability is quite dependent on the balance between suspended and granular biomass contents. Therefore, in this work, the prediction of SVI, VSS, and TSS of mature AGS was successfully studied by MLR techniques using data obtained by QIA. As a result, good prediction models were obtained for the SVI ( $\mathrm{R}^{2}$ of 0.975$)$, granules TSS ( $R^{2}$ of 0.985$)$, flocs TSS ( $R^{2}$ of 0.971$)$, granules VSS $\left(R^{2}\right.$ of 0.984$)$ and flocs VSS ( $\mathrm{R}^{2}$ of 0.986$)$. Furthermore, the models explanatory variables were used to enlighten the main dependencies for each of the studied parameters. However, care should be taken in extending this model to different sets of conditions from the current study, such as the presence of toxic substances, with further work being developed to that effect.

It is expected that QIA could be applied in the future for monitoring structural and morphological changes in biomass induced by operational changes and for the diagnostic of other settling ability dysfunctions in AGS such as filamentous outgrowth. Indeed, the estimation of the granular fraction ratio, from the predicted TSS and VSS, was also 
successful ( $\mathrm{R}^{2}$ of 0.985$)$. Thus, the application of QIA and chemometric techniques in full scale AGS systems can be considered as a promising tool contributing to the process optimization.

\section{Acknowledgements}

The authors thank the Portuguese Foundation for Science and Technology (FCT) under the scope of the strategic funding of UID/BIO/ 04469 unit, BioTecNorte operation (NORTE-01-0145-FEDER-000004) funded by the European Regional Development Fund under the scope of Norte2020 - Programa Operacional Regional do Norte and the project AGeNT - PTDC/BTA-BTA/31264/2017 (POCI-01-0145-FEDER031264). We would also like to thank the scientific collaboration under the FCT project UID/Multi/50016/2019. Cristiano Leal is recipient of a fellowship supported by a doctoral advanced training (call NORTE-692015-15) funded by the European Social Fund under the scope of Norte2020 - Programa Operacional Regional do Norte. A. Val del Rio is supported by Xunta de Galicia (ED418B 2017/075) and program Iacobus $(2017 / 2018)$.

\section{References}

[1] D.H. Eikelboom, Process Control of Activated Sludge Plants by Microscopic Investigation, IWA Publishing, London, 2000.

[2] D. Jenkins, M.G. Richard, G.T. Daiger, Manual on the causes and control of activated sludge bulking, foaming, and other separation problems, IWA Publishing, London, 2003

[3] P. Duchène, E. Cotteux, La problématique des disfonctionnements biologiques: bulking et moussage des boues activées", Trib. l'eau 59 (1998) 59-66.

[4] S. Bengtsson, M. de Blois, B.M. Wilén, D. Gustavsson, A comparison of aerobic granular sludge with conventional and compact biological treatment technologies, Environ. Technol. (2018) 1-10.

[5] M.K. De Kreuk, J.J. Heijnen, M.C.M. Van Loosdrecht, Simultaneous COD, nitrogen, and phosphate removal by aerobic granular sludge, Biotechnol. Bioeng. 90 (2005) 761-769.

[6] S.F. Corsino, M. Capodici, M. Torregrossa, G. Viviani, Fate of aerobic granular sludge in the long-term: the role of EPSs on the clogging of granular sludge porosity, J. Environ. Manage. 183 (2016) 541-550.

[7] M. Caluwé, T. Dobbeleers, J. D’aes, S. Miele, V. Akkermans, D. Daens, L. Geuens, F. Kiekens, R. Blust, J. Dries, Formation of aerobic granular sludge during the treatment of petrochemical wastewater, Bioresour. Technol. 238 (2017) 559-567.

[8] W. Xue, T. Hao, H.R. Mackey, X. Li, R.C. Chan, G. Chen, The role of sulfate in aerobic granular sludge process for emerging sulfate-laden wastewater treatment, Water Res. 124 (2017) 513-520.

[9] D. Wei, K. Zhang, S. Wang, B. Sun, N. Wu, W. Xu, B. Du, Q. Wei, Characterization of dissolved organic matter released from activated sludge and aerobic granular sludge biosorption processes for heavy metal treatment via a fluorescence approach, Int. Biodeterior. Biodegrad. 124 (2017) 326-333.

[10] I.H. Farooqi, F. Basheer, Treatment of Adsorbable Organic Halide (AOX) from pulp and paper industry wastewater using aerobic granules in pilot scale SBR, J. Water Process Eng. 19 (2017) 60-66.

[11] A. Cydzik-Kwiatkowska, I. Wojnowska-Baryła, M. Szatkowski, L. Smoczyński, Biochemical conversions and biomass morphology in a long-term operated SBR with aerobic granular sludge, Desalin. Water Treat. 51 (2013) 2261-2268.

[12] C. Zhang, H. Zhang, F. Yang, Diameter control and stability maintenance of aerobic granular sludge in an A/O/A SBR, Sep. Purif. Technol. 149 (2015) 362-369.

[13] M. Verawaty, S. Tait, M. Pijuan, Z. Yuan, P.L. Bond, Breakage and growth towards a stable aerobic granule size during the treatment of wastewater, Water Res. 47 (2013) 5338-5349.

[14] R.H. Ribeiro da Costa, E. Morgenroth, N. Derlon, D.G. Weissbrodt, V. Manguin, J. Wagner, Effect of particulate organic substrate on aerobic granulation and operating conditions of sequencing batch reactors, Water Res. 85 (2015) 158-166.

[15] R. Jenné, N. Bannada, G. Gins, J. Deurich, Use of image analysis for sludge characterisation: studying the relation between floc shape and sludge settleability, Water Sci. Technol. 54 (2006) 167-174.

[16] A.L. Amaral, E.C. Ferreira, Activated sludge monitoring of a wastewater treatment plant using image analysis and partial least squares regression, Anal. Chim. Acta 544 (2005) 246-253.

[17] K. Grijspeerdt, W. Verstraete, Image analysis to estimate the settleability and concentration of activated sludge, Water Res. 31 (1997) 1126-1134.

[18] D.P. Mesquita, O. Dias, A.M.A. Dias, A.L. Amaral, E.C. Ferreira, Correlation between sludge settling ability and image analysis information using partial least squares, Anal. Chim. Acta 642 (2009) 94-101.

[19] D.P. Mesquita, A.L. Amaral, E.C. Ferreira, Identifying different types of bulking in an activated sludge system through quantitative image analysis, Chemosphere 85 (2011) 643-652.

[20] H. Boztoprak, Y. Özbay, D. Güçlü, M. Küçükhemek, Prediction of sludge volume index bulking using image analysis and neural network at a full-scale activated sludge plant, Desalin. Water Treat. 1-11 (2015).

[21] M. Da Motta, M.N. Pons, N. Roche, Monitoring filamentous bulking in activated sludge systems fed by synthetic or municipal wastewater, Bioprocess Biosyst. Eng. 25 (2003) 387-393.

[22] E. Liwarska-Bizukojc, M. Bizukojc, Digital image analysis to estimate the influence of sodium dodecyl sulphate on activated sludge flocs, Process Biochem. 40 (2005) 2067-2072.

[23] C. Lopez, M.N. Pons, E. Morgenroth, Evaluation of microscopic techniques (epifluorescence microscopy, CLSM, TPE-LSM) as a basis for the quantitative image analysis of activated sludge, Water Res. 39 (2005) 456-468.

[24] D. Pandolfi, M.N. Pons, M. Da Motta, Characterization of PHB storage in activated sludge extended filamentous bacteria by automated colour image analysis, Biotechnol. Lett. 29 (2007) 1263-1269.

[25] R. Jenné, E.N. Banadda, I. Smets, J. Deurinck, J. Van Impe, Detection of filamentous bulking problems: developing an image analysis system for sludge composition monitoring, Microsc. Microanal. 13 (2007) 36-41.

[26] C. Leal, A.L. Amaral, M.L. Costa, Microbial-based evaluation of foaming events in full-scale wastewater treatment plants by microscopy survey and quantitative image analysis, Environ. Sci. Pollut. Res. 23 (2016) 15638-15650.

[27] J. Kwak, B. Khang, E. Kim, H. Kim, Estimation of biochemical oxygen demand based on dissolved organic carbon, UV absorption, and fluorescence measurements, J. Chem. 2013 (2013)

[28] M. Park, T. Anumol, S.A. Snyder, Modeling approaches to predict removal of trace organic compounds by ozone oxidation in potable reuse applications, Environ. Sci. Water Res. Technol. 1 (2015) 699-708.

[29] A. Abreu, J.C. Costa, P. Araya-Kroff, E.C. Ferreira, M.M. Alves, Quantitative image analysis as a diagnostic tool for identifying structural changes during a revival process of anaerobic granular sludge, Water Res. 41 (2007) 1473-1480.

[30] J.C. Costa, I. Moita, E.C. Ferreira, M.M. Alves, Morphology and physiology of anaerobic granular sludge exposed to an organic solvent, J. Hazard. Mater. 167 (2009) 393-398.

[31] J.C. Costa, M.M. Alves, E.C. Ferreira, A chemometric tool to monitor high-rate anaerobic granular sludge reactors during load and toxic disturbances, Biochem. Eng. J. 53 (2010) 38-43.

[32] APWA Standard Methods for the Examination of Water and Wastewater 20th Ed. American Public Health Association, American Water Works Association and Water Environmental Federation, Washington DC, 1998.

[33] D.P. Mesquita, A.L. Amaral, E.C. Ferreira, Characterization of activated sludge abnormalities by image analysis and chemometric techniques, Anal. Chim. Acta 705 (2011) 235-242.

[34] A. Amaral, Image Analysis in Biotechnological Processes: Applications to Wastewater Treatment, University of Minho, 2003.

[35] H. Zou, G.C. Du, W.Q. Ruan, J. Chen, Role of nitrate in biological phosphorus removal in a sequencing batch reactor, World J. Microbiol. Biotechnol. 22 (2006) 701-706.

[36] J.P. Bassin, R. Kleerebezem, M. Dezotti, M.C.M. van Loosdrech, Simultaneous nitrogen and phosphate removal in aerobic granular sludge reactors operated at different temperatures, Water Res. 46 (2012) 3805-3816.

[37] B. Long, X. Xuan, C. Yang, L. Zhang, Y. Cheng, J. Wang, Stability of aerobic granular sludge in a pilot scale sequencing batch reactor enhanced by granular particle size control, Chemosphere 225 (2019) 460-469.

[38] M. Pronk, M.K. de Kreuk, B. de Bruin, P. Kamminga, R. Kleerebezem, M.C.M. van Loosdrecht, Full scale performance of the aerobic granular sludge process for sewage treatment, Water Res. 84 (2015) 207-217.

[39] P. Świątczak, A. Cydzik-Kwiatkowska, Performance and microbial characteristics of biomass in a full-scale aerobic granular sludge wastewater treatment plant, Environ. Sci. Pollut. Res. 25 (2018) 1655-1669.

[40] M.H. Ab Halim, A. Nor Anuar, N.S. Abdul Jamal, S.I. Azmi, Z. Ujang, M.M. Bob, Influence of high temperature on the performance of aerobic granular sludge in biological treatment of wastewater, J. Environ. Manage. 184 (2016) 271-280.

[41] T. Etterer, P.A. Wilderer, Generation and properties of aerobic granular sludge, Water Sci. Technol. 43 (2001) 19-26.

[42] D.P. Mesquita, O. Dias, A.L. Amaral, E.C. Ferreira, Relationship Between Sludge Volume Index and Biomass Structure Within Activated Sludge Systems Atas do XVII COBEQ - Congresso Brasileiro de Engenharia Química, (Recife), 2008 CD-ROM, 7 p 